Article

\title{
Secondary Metabolites from Penicillium pinophilum SD-272, a Marine Sediment-Derived Fungus
}

\author{
Ming-Hui Wang ${ }^{1,2}$, Xiao-Ming $\mathrm{Li}^{1}{ }^{1}$, Chun-Shun $\mathrm{Li}^{1}{ }^{1}$, Nai-Yun $\mathrm{Ji}^{3{ }^{3, *}}$ and Bin-Gui Wang ${ }^{1, *}$
}

1 Key Laboratory of Experimental Marine Biology, Institute of Oceanology, Chinese Academy of Sciences, Nanhai Road 7, Qingdao 266071, China; E-Mails: wangmh29@yahoo.cn (M.-H.W.); lixmqd@yahoo.com.cn (X.-M.L.); lichunshun@ms.qdio.ac.cn (C.-S.L.)

2 University of Chinese Academy of Sciences, Yuquan Road 19A, Beijing 100049, China

3 Key Laboratory of Coastal Biology and Bioresource Utilization, Yantai Institute of Coastal Zone Research, Chinese Academy of Sciences, Chunhui Road 17, Yantai 264003, China

* Authors to whom correspondence should be addressed; E-Mails: nyji@yic.ac.cn (N.-Y.J.); wangbg@ms.qdio.ac.cn (B.-G.W.); Tel.: +86-535-210-9176 (N.-Y.J.); +86-532-8289-8553 (B.-G.W.); Fax: +86-535-210-9000 (N.-Y.J.); +86-532-8289-8553 (B.-G.W.).

Received: 14 March 2013; in revised form: 24 May 2013 / Accepted: 27 May 2013 /

Published: 21 June 2013

\begin{abstract}
Two new secondary metabolites, namely, pinodiketopiperazine A (1) and 6,7-dihydroxy-3-methoxy-3-methylphthalide (2), along with alternariol 2,4-dimethyl ether (3) and L-5-oxoproline methyl ester (4), which were isolated from a natural source for the first time but have been previously synthesized, were characterized from the marine sediment-derived fungus Penicillium pinophilum SD-272. In addition, six known metabolites (5-10) were also identified. Their structures were elucidated by analysis of the NMR and mass spectroscopic data. The absolute configuration of compound $\mathbf{1}$ was determined by experimental and calculated ECD spectra. Compound $\mathbf{2}$ displayed potent brine shrimp (Artemia salina) lethality with $\mathrm{LD}_{50} 11.2 \mu \mathrm{M}$.
\end{abstract}

Keywords: sediment; Penicillium pinophilum; secondary metabolite; brine shrimp lethality

\section{Introduction}

Marine fungi are known to be a prolific source of biologically active natural products which might be useful for drug discovery [1,2]. As a special ecosystem, marine sediment provides an abundant of fungal resources, which yielded various secondary metabolites with novel structures and interesting biological 
activities [3-5]. In the course of our search for bioactive metabolites from marine-derived fungi [6-11], a strain of Penicillium pinophilum SD-272, which was isolated from sediment samples collected from the estuary of the Pearl River in South China Sea, attracted our attention. The EtOAc extract of the culture extract yielded a new diketopiperazine derivative, pinodiketopiperazine A (1), a new phthalide derivative, 6,7-dihydroxy-3-methoxy-3-methylphthalide (2), as well as alternariol 2,4-dimethyl ether (3) $[12,13]$ and L-5-oxoproline methyl ester (4) [14], which were isolated from a natural source for the first time but have been previously synthesized (Figure 1). In addition, six known compounds (5-10) were also isolated and identified. We present herein the isolation, structural elucidation, absolute configuration determination, and biological activity of these compounds.

Figure 1. Structures of the isolated compounds 1-10 and the reference compound 11.

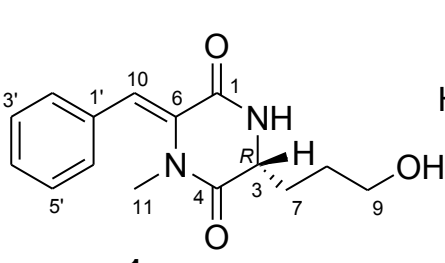

1

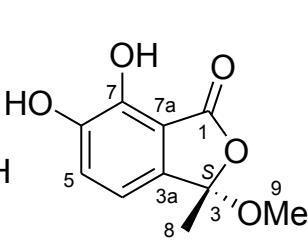

2

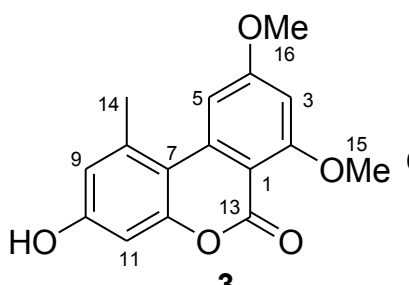

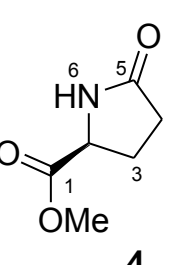

4

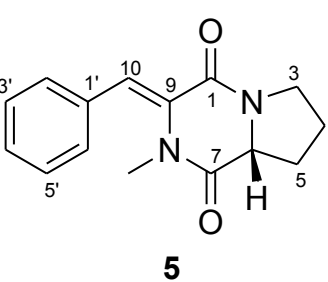

5<smiles>O=C1N[C@@H](Cc2ccccc2)C(=O)N2CC(O)CC12</smiles>

6

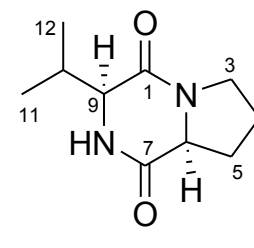

7<smiles>[M]O[C@H]1OC(=O)c2cc(O)c(C)c(O)c21</smiles>

8
3<smiles>COc1cc(O)c2c(c1)C1=C[C@H](C)[C@@H](Cl)C[C@]1(C)OC2=O</smiles>

$\mathrm{R} 9 \mathrm{R}=\beta-\mathrm{OH}$ $10 \mathrm{R}=\alpha-\mathrm{OH}$

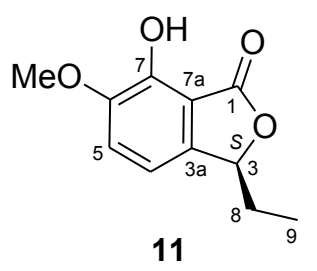

11

\section{Results and Discussion}

\subsection{Structure Elucidation of the New Compounds}

Compound 1 was obtained as yellowish oil and HRESIMS data established its molecular formula as $\mathrm{C}_{15} \mathrm{H}_{18} \mathrm{~N}_{2} \mathrm{O}_{3}$, indicating eight degrees of unsaturation. In the ${ }^{1} \mathrm{H}$ NMR spectrum (Table 1), signals for a mono-substituted phenyl group (H-2'-H-6') and a tri-substituted double bond (H-10) were presented, as well as a nitrogenated or oxygenated methine (H-3), three methylenes (H-7-H-9), and a tertiary methyl (H-11) group. The ${ }^{13} \mathrm{C}$ and DEPT NMR spectroscopic data (Table 1) exhibited the presence of 15 carbon signals which were further classified into one methyl, three methylenes (with one oxygenated), seven methines, and four quaternary (with two amide ester carbonyl and two olefinic quaternary) carbon atoms. The ${ }^{1} \mathrm{H}^{-}{ }^{1} \mathrm{H}$ COSY spectrum (Figure 2) revealed two spin systems corresponding to two substructures, with the first one being a phenyl group which connected to the double bond as evidenced by the HMBC correlation from H-10 to C-2'/C-6' (Figure 2). The second substructure being started from an exchangeable $\mathrm{NH}$ proton (NH-2), followed by a methine proton $\mathrm{H}-3$, which connected to a straight chain consisting of three methylene groups $\left(\mathrm{CH}_{2}-7-\mathrm{CH}_{2}-9\right)$ and terminated with an $\mathrm{OH}$ group (Figure 2). The connection of the above substructures in $\mathbf{1}$ as mentioned above was established by detailed inspection of the key HMBC correlations from $\mathrm{H}-10$ to $\mathrm{C}-1$, from $\mathrm{H}_{3}-11$ to $\mathrm{C}-4$ and $\mathrm{C}-6$, and from $\mathrm{NH}-2$ 
to $\mathrm{C}-4$ and $\mathrm{C}-6$. The structure of compound 1 was therefore elucidated as shown in Figure 1. A trivial name pinodiketopiperazine A was assigned to this compound.

Figure 2. Key COSY (bold lines) and HMBC (arrows) correlations for compounds $\mathbf{1}$ and 2.

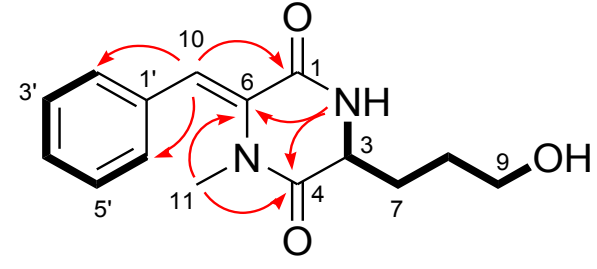

1

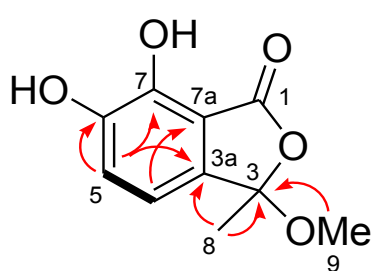

2

Table 1. ${ }^{1} \mathrm{H}$ - and ${ }^{13} \mathrm{C}-\mathrm{NMR}$ data of compound 1 in DMSO- $d_{6}{ }^{\mathrm{a}}$.

\begin{tabular}{cccccc}
\hline No. & $\boldsymbol{\delta}_{\mathbf{C}}$ & $\boldsymbol{\delta}_{\mathbf{H}}(\boldsymbol{J}$ in Hz $)$ & No. & $\boldsymbol{\delta}_{\mathbf{C}}$ & $\boldsymbol{\delta}_{\mathbf{H}}(\boldsymbol{J}$ in Hz $)$ \\
\hline 1 & $162.5, \mathrm{C}$ & & 9 & $60.1, \mathrm{CH}_{2}$ & $3.40, \mathrm{~m}$ \\
$2-\mathrm{NH}$ & & $8.62, \mathrm{~d}(2.8)$ & 10 & $118.1, \mathrm{CH}$ & $6.97, \mathrm{~s}$ \\
3 & $55.0, \mathrm{CH}$ & $3.94, \mathrm{~m}$ & 11 & $34.5, \mathrm{CH}_{3}$ & $2.73, \mathrm{~s}$ \\
4 & $167.9, \mathrm{C}$ & & $1^{\prime}$ & $133.8, \mathrm{C}$ & \\
6 & $132.4, \mathrm{C}$ & & $2^{\prime} / 6^{\prime}$ & $129.2, \mathrm{CH}$ & $7.42, \mathrm{~d}(7.5)$ \\
7 & $30.6, \mathrm{CH}_{2}$ & a $1.79, \mathrm{~m}$ & $3^{\prime} / 5^{\prime}$ & $128.3, \mathrm{CH}$ & $7.30, \mathrm{t}(7.5)$ \\
& & b $1.71, \mathrm{~m}$ & $4^{\prime}$ & $128.1, \mathrm{CH}$ & $7.34, \mathrm{t}(7.5)$ \\
8 & $28.0, \mathrm{CH}_{2}$ & $1.51, \mathrm{~m}$ & $\mathrm{OH}$ & $4.48, \mathrm{br} \mathrm{s}$ \\
\hline \multicolumn{5}{c}{${ }^{a}$ Measured at $500 \mathrm{MHz}$ for ${ }^{1} \mathrm{H}$ and $125 \mathrm{MHz}$ for ${ }^{13} \mathrm{C}}$.
\end{tabular}

${ }^{\mathrm{a}}$ Measured at $500 \mathrm{MHz}$ for ${ }^{1} \mathrm{H}$ and $125 \mathrm{MHz}$ for ${ }^{13} \mathrm{C}$.

To determine the absolute configuration of 1, the electronic circular dichroism (ECD) was experimentally recorded and it showed negative Cotton effects at 203 and $288 \mathrm{~nm}$ (Figure 3). The theoretical ECD was then calculated using the time-dependent DFT (density function theory) method at the B3LYP/6-31G(d) level and was compared with that of the experimental data. The side chain at C-3 in 1 was truncated to a methyl (1a and 1b) (Figure 4) since it contributes little to the ECD spectrum $[15,16]$. The results showed that, although a slightly peaked shift was observed, the calculated curve of 1a (with $3 R$-configuration) was in good agreement with that of the experimental one (Figure 3), which indicated that the absolute configuration at C-3 of $\mathbf{1}$ was $R$.

Figure 3. Experimental and calculated electronic circular dichroism (ECD) spectra of 1a $(3 R)$ and $\mathbf{1 b}(3 S)$.

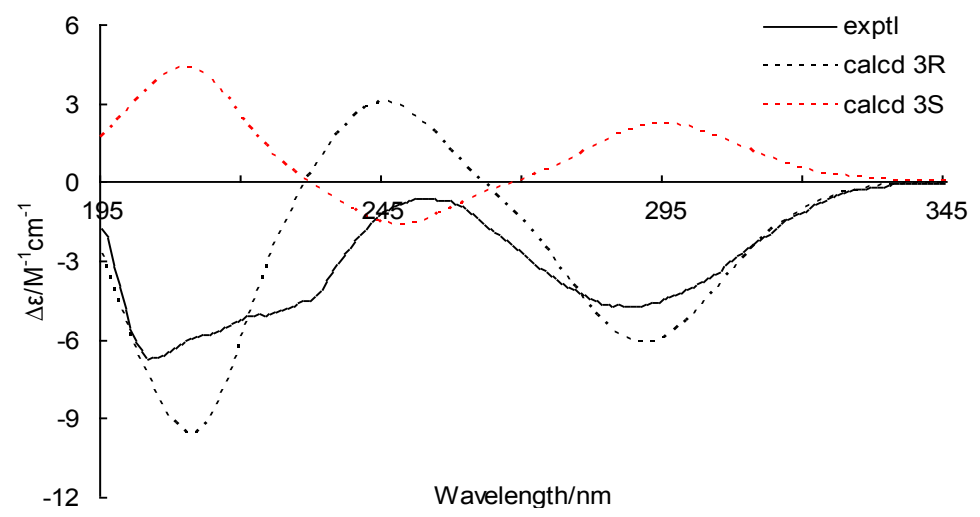


Figure 4. Model compounds 1a and $1 \mathbf{b}$ for ECD calculations.<smiles>C[C@@H]1NC(=O)C(=Cc2ccccc2)N(C)C1=O</smiles>

Compound 2 was obtained as white amorphous powder and its molecular formula $\mathrm{C}_{10} \mathrm{H}_{10} \mathrm{O}_{5}$ was determined on the basis of the positive HRESIMS. Detailed analysis of the NMR spectroscopic data (Table 2) revealed that the structure of $\mathbf{2}$ was similar to $(S)$-3-ethyl-7-hydroxy-6-methoxyphthalide (11, Figure 1) [17]. However, the C-6 OMe group in 11 was replaced by $\mathrm{OH}$ group in $\mathbf{2}$ as evidenced by the fact that the resonances corresponding to the C-6 OMe group at $\delta_{\mathrm{H}} 3.84 / \delta_{\mathrm{C}} 56.2$ in the NMR spectra of 11 disappeared in that of 2 . In addition, the proton signals at $\delta_{\mathrm{H}} 5.51(\mathrm{H}-3), 1.83 / 2.30(\mathrm{H}-8)$, and $0.95(\mathrm{H}-9)$ as well as the carbon signals at $\delta_{\mathrm{C}} 83.3(\mathrm{CH}, \mathrm{C}-3), 25.9\left(\mathrm{CH}_{2}, \mathrm{C}-8\right)$, and $9.1\left(\mathrm{CH}_{3}, \mathrm{C}-9\right)$ in the NMR spectra of 11 were missing in that of 2. Instead, signals resonating at $\delta_{\mathrm{C}} 108.6(\mathrm{C})$ for a ketal carbon (C-3), at $\delta_{\mathrm{H}} 1.74 / \delta_{\mathrm{C}} 25.6$ for a methyl group $\left(\mathrm{CH}_{3}-8\right)$, and at $\delta_{\mathrm{H}} 2.94 / \delta_{\mathrm{C}} 52.4$ for an OMe group $\left(\mathrm{OCH}_{3}-9\right)$, were observed in the NMR spectra of 2 (Table 2). The HMBC correlations from H-8 and H-9 to C-3 and from $\mathrm{H}-8$ to C-3a supported the above deduction (Figure 2). The structure of $\mathbf{2}$ was thus determined as 6,7-dihydroxy-3-methoxy-3-methylphthalide. To unambiguously determine the absolute configuration, compound 2 was also submitted to ECD measurement and calculation. However, no obvious Cotton effect was observed in the experiment. Thus, ECD was not applicable to resolve the absolute configuration of compound 2. By comparison of its optical rotation $\left([\alpha]_{\mathrm{D}}{ }^{27}-8.3, c 0.12, \mathrm{CHCl}_{3}\right)$ with that of the (S)-3-ethyl-7-hydroxy-6-methoxyphthalide (11) $\left([\alpha]_{\mathrm{D}}{ }^{25}-71.5, c 0.10, \mathrm{CHCl}_{3}\right)$ [17], the $S$-configuration at C-3 was tentatively deduced to this compound.

Table 2. ${ }^{1} \mathrm{H}$ - and ${ }^{13} \mathrm{C}-\mathrm{NMR}$ data of compound 2 in DMSO- $d_{6}{ }^{\mathrm{a}}$.

\begin{tabular}{cccccc}
\hline No. & $\boldsymbol{\delta}_{\mathbf{C}}$ & $\boldsymbol{\delta}_{\mathbf{H}}(\boldsymbol{J}$ in Hz) & No. & $\boldsymbol{\delta}_{\mathbf{C}}$ & $\boldsymbol{\delta}_{\mathbf{H}}(\boldsymbol{J}$ in $\mathbf{H z})$ \\
\hline 1 & $167.6, \mathrm{C}$ & & 6 & $146.6, \mathrm{C}$ & \\
3 & $108.6, \mathrm{C}$ & & 7 & $151.1, \mathrm{C}$ & \\
$3 \mathrm{a}$ & $132.9, \mathrm{C}$ & & $7 \mathrm{a}$ & $114.6, \mathrm{C}$ & \\
4 & $121.2, \mathrm{CH}$ & $6.84, \mathrm{~d}(8.5)$ & 8 & $25.6, \mathrm{CH}_{3}$ & $1.74, \mathrm{~s}$ \\
5 & $125.7, \mathrm{CH}$ & $7.01, \mathrm{~d}(8.5)$ & 9 & $52.4, \mathrm{CH}_{3}$ & $2.94, \mathrm{~s}$ \\
\hline \multicolumn{6}{c}{${ }^{\mathrm{a}}$ Measured at $500 \mathrm{MHz}$ for ${ }^{1} \mathrm{H}$ and $125 \mathrm{MHz}$ for ${ }^{13} \mathrm{C}}$.
\end{tabular}

Compounds 3 and $\mathbf{4}$ were previously reported as synthetic products and were obtained and described here for the first time as naturally occurring fungal metabolites [12-14]. The NMR data for compound 3 was not published previously and the fully assigned ${ }^{1} \mathrm{H}$ and ${ }^{13} \mathrm{C}$ NMR data for this compound were provided in the Experimental Section.

In addition to compounds 1-4, six known secondary metabolites including $\mathrm{N}$-methylphenyldehydroalanyl-L-prolin-anhydrid (5) [18,19], cyclo-trans-4-OH-(D)-Pro-(D)-Phe (6) [20], cyclo(D)-Pro-(D)-Val (7) [20], rubralide C (8) [21], 5'-epialtenuene (9) [22] and altenuene (10) [22] 
(Figure 1), were also isolated, and their structures were elucidated by comparing the NMR data with those of literature reports [18-22].

\subsection{Biological Activities of the Isolated Compounds}

The isolated compounds 1-10 were evaluated for the brine shrimp (Artemia salina) lethal activity and antibacterial activity. Among them, compound 2 was found to possess potent lethality with $\mathrm{LD}_{50} 11.2 \mu \mathrm{M}$, which is more active than that of the positive control colchicine (with $\mathrm{LD}_{50} 92.1 \mu \mathrm{M}$ ), but the other tested compounds only displayed weak activity. In the antibacterial assay, compounds $\mathbf{1}, \mathbf{3}, \mathbf{5}-\mathbf{8}$, and positive control chloromycetin displayed inhibitory activity against Escherichia coli, causing the 10.0, 9.0, 8.0, 8.0, 7.0, 10.0, and $15.0 \mathrm{~mm}$ zones of inhibition at $20 \mu \mathrm{g} / \mathrm{disk}$, respectively.

\section{Experimental Section}

\subsection{General}

NMR Spectra was recorded on a Bruker Avance-500 MHz spectrometer $\left(500 \mathrm{MHz}\right.$ for ${ }^{1} \mathrm{H}$ and $125 \mathrm{MHz}$ for ${ }^{13} \mathrm{C}$ ) and chemical shifts were recorded as $\delta$ values. Low and high ESI-Mass spectra were performed on a VG Auto spec 3000 spectrometer. Optical rotations were obtained on Optical Activity A-55 polarimeter. UV Spectra were measured in methanol on a Lengguang Gold S54 spectrophotometer. Silica gel $\left(\mathrm{SiO}_{2} ; 100-200\right.$ mesh, 200-300 mesh and $\left.\mathrm{GF}_{254}\right)$ for column chromatography and preparative thin-layer chromatography were produced by Qingdao Haiyang Chemical Group Corporation. RP-18 reverse-phase silica gel (40-63 $\mu \mathrm{m})$ and Sephadex LH-20 were purchased from the Merck Corporation. All solvents were distilled to use.

\subsection{Fungal Material}

The fungal strain Penicillium pinophilum SD-272 was isolated from the sediment sample collected from the estuary of the Pearl River in South China Sea, in October 2010. The fungal identification was achieved by analysis of the ITS region of its rDNA as described previously [23]. The sequence data obtained from the fungus has been submitted to GeneBank with accession number KC 427134. A voucher specimen was stored at the Key Laboratory of Experimental Marine Biology of the Institute of Oceanology, Chinese Academy of Sciences.

\subsection{Fermentation}

One hundred 1000-mL Erlenmeyer flasks, each contains $300 \mathrm{~mL}$ liquid medium (sucrose 2\%, peptone $0.5 \%$, yeast extract $0.3 \%$, monosodium glutamate $1 \%$, mannitol $2 \%$, potato flour $0.4 \%$, seawater, pH 6.5), were sterilized at $116^{\circ} \mathrm{C}$ for $20 \mathrm{~min}$ and cooled to room temperature subsequently. A piece of mycelium (size $3 \mathrm{~cm}^{2}$ ) growing on malt agar plate was inoculated into 1000-mL Erlenmeyer flask. Static fermentation was then conducted at $28^{\circ} \mathrm{C}$ for 35 days. 


\subsection{Extraction and Isolation}

The culture broth was filtrated using filter paper and separated into mycelia and culture broth. The air-dried mycelia were immersed in acetone- $\mathrm{H}_{2} \mathrm{O}(4: 1)$ with ultrasonic processor for 20 min and then extracted three times with ethyl acetate, while the culture broth was stirred for three times with ethyl acetate and then concentrated to obtain an organic extract. Since the two extract show similar HPLC and TLC profiles, they were combined to afford a crude extract $(50.2 \mathrm{~g})$ for further purification.

The crude extract was subjected to vacuum liquid chromatography (VLC) on silica gel eluting with step solvents of increasing polarity (from petroleum ether to $\mathrm{MeOH}$ ) to yield 9 fractions (Fr.1-Fr.9). Fr.1 was subjected to Sephadex LH-20 (acetone) and preparative-TLC to afford 2 (4.5 mg). Fr.3 was separated by column chromatography $(\mathrm{CC})$ on Lobar LiChroprep $\mathrm{C}_{18}$ eluting with $\mathrm{MeOH}-\mathrm{H}_{2} \mathrm{O}$ gradient to give five sub-fractions (Fr.3.1-Fr.3.5). Fr.3.3 was then chromatographed on silica gel eluting with $\mathrm{CHCl}_{3}-\mathrm{MeOH}$ gradient (60:1) and further purified by Sephadex LH-20 (MeOH) to afford 3 (9.4 mg), 5 (7.1 mg), and $8(5.1 \mathrm{mg})$. Fr.4 was also further separated by $\mathrm{CC}$ on silica gel to give five subfractions (Fr.4.1-Fr.4.5). Fr.4.2 was purified by CC on Sephadex LH-20 (MeOH) and by semi-preparative HPLC using $\mathrm{MeOH}-\mathrm{H}_{2} \mathrm{O}$ gradient (50:50) to yield 1 (4.1 mg, $\left.t_{R} 25.6 \mathrm{~min}\right), 7$ (7.0 mg, $t_{R} 18.1 \mathrm{~min}$ ), and 6 (28.7 mg, $t_{R} 20.8 \mathrm{~min}$ ). Fr.4.4 was subjected to $\mathrm{CC}$ on silica gel using $\mathrm{CHCl}_{3}-\mathrm{MeOH}$ gradient (50:1) and purified by Sephadex LH-20 (acetone) to get $9(10.2 \mathrm{mg}), \mathbf{1 0}(5.4 \mathrm{mg})$, and 4 (14.6 mg).

Compound 1: yellowish oil; $[\alpha]_{\mathrm{D}}{ }^{27}-224\left(c\right.$ 0.25, MeOH); UV (MeOH) $\lambda_{\max }(\log \varepsilon) 200(4.31), 291$ (4.09) nm; CD $\lambda_{\max }(\Delta \varepsilon) 195(-4.36), 203(-16.79), 252(-1.56), 288(-11.82) \mathrm{nm} ;{ }^{1} \mathrm{H}$ and ${ }^{13} \mathrm{C}$ NMR data, see Table 1; HRESIMS $m / z 275.1398[\mathrm{M}+\mathrm{H}]^{+}$(calcd for $\mathrm{C}_{15} \mathrm{H}_{19} \mathrm{~N}_{2} \mathrm{O}_{3}, 275.1390$ ), 297.1216 $[\mathrm{M}+\mathrm{Na}]^{+}$(calcd for $\mathrm{C}_{15} \mathrm{H}_{18} \mathrm{~N}_{2} \mathrm{O}_{3} \mathrm{Na}, 297.1215$ ).

Compound 2: white amorphous powder; $[\alpha]_{\mathrm{D}}{ }^{27}-8.3\left(c 0.12, \mathrm{CHCl}_{3}\right) ; \mathrm{UV}(\mathrm{MeOH}) \lambda_{\max }(\log \varepsilon) 215$ (4.54), 237 (4.05), 331 (4.01) nm; ${ }^{1} \mathrm{H}$ and ${ }^{13} \mathrm{C}$ NMR data, see Table 2; HRESIMS $\mathrm{m} / z 211.0597$ $[\mathrm{M}+\mathrm{H}]^{+}$(calcd for $\left.\mathrm{C}_{10} \mathrm{H}_{11} \mathrm{O}_{5}, 211.0607\right)$.

Compound 3: white amorphous powder; UV (MeOH) $\lambda_{\max }(\log \varepsilon) 200$ (3.69), 217 (3.58), 255 (3.75), 288 (3.27), 300 (3.26), 333 (3.29) nm; ${ }^{1} \mathrm{H}$ NMR data (at $500 \mathrm{MHz}$ in DMSO-d ${ }_{6}$ ): $\delta_{\mathrm{H}} 6.69$ (s, H-3), 7.24 (s, H-5), 6.65 (s, H-9), 6.53 (s, H-11), 10.25 (s, OH-10), 2.73 (s, H-14), 3.89 (s, H-15), 3.94 (s, H-16); ${ }^{13} \mathrm{C}$ NMR data (at $125 \mathrm{MHz}$ in DMSO- $d_{6}$ ): $\delta_{\mathrm{C}} 102.0$ (C, C-1), 163.5 (C, C-2), 97.3 (CH, C-3), 164.5 (C, C-4), 102.1 (CH, C-5), 139.8 (C, C-6), 116.6 (C, C-7), 137.7 (C, C-8), 116.6 (CH, C-9), 158.4 (C, C-10), 100.7 (CH, C-11), 153.5 (C, C-12), 156.1 (C, C-13), $24.8\left(\mathrm{CH}_{3}, \mathrm{C}-14\right), 56.1\left(\mathrm{CH}_{3}, \mathrm{C}-15\right), 55.6\left(\mathrm{CH}_{3}\right.$, $\mathrm{C}-16)$. HRESIMS $m / z 287.0918[\mathrm{M}+\mathrm{H}]^{+}$(calcd for $\mathrm{C}_{16} \mathrm{H}_{15} \mathrm{O}_{5}, 287.0920$ ).

\subsection{Computational Details}

Conformational searches for $\mathbf{1 a}$ and $\mathbf{1 b}$ were performed via the Dreiding force field in MarvinSketch regardless of rotations of methyl and hydroxyl groups [24], the geometries of which were further optimized at the B3LYP/6-31G (d) level in methanol to give the conformers (three for $\mathbf{1 a}$ and two for $\mathbf{1 b}$, see Figures 5 and 6 , respectively) within a $3 \mathrm{kcal} / \mathrm{mol}$ energy threshold from the global minimum without vibrational imaginary frequencies. The optimized conformers were then subjected to the calculations of ECD spectra using the time-dependent density functional theory (TD-DFT) method at the 
B3LYP/6-31G(d) level, which were drawn via SpecDic software with sigma $=0.25$ and UV shift $=-20 \mathrm{~nm}$ (magnified by 0.5 times) and weighted by Boltzmann distribution (Figure 3), respectively [25]. All the above calculations were performed with the integral equation formalism variant polarizable continuum model (IEF-PCM) as implemented in Gaussian 09 [26].

Figure 5. Conformers with populations of $\mathbf{1 a}$ (in $\mathrm{MeOH}$ ).

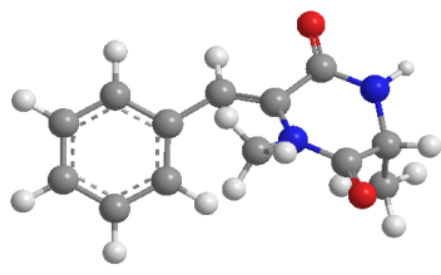

$24.5 \%$

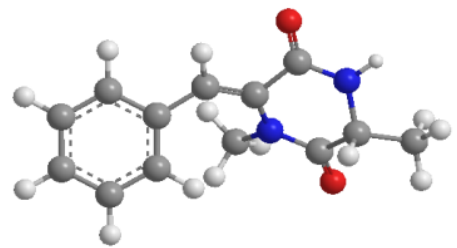

$37.4 \%$

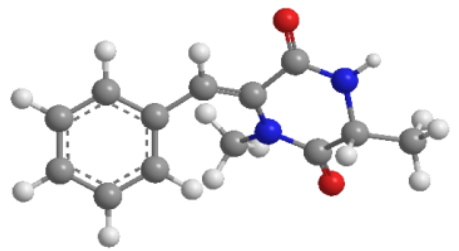

$38.1 \%$

Figure 6. Conformers with populations of $\mathbf{1 b}$ (in $\mathrm{MeOH}$ ).

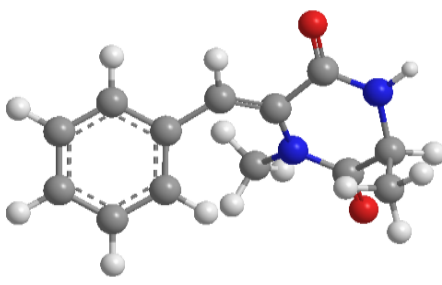

$39.7 \%$

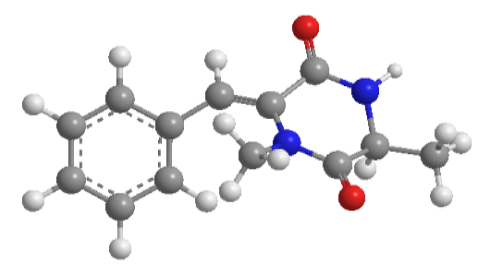

$60.3 \%$

\subsection{Antibacterial Assays}

The experiments were performed using the disk diffusion method [27]. Chloromycetin was used as positive control.

\subsection{Brine Shrimp (Artemia salina) Lethality Assay}

The assay was carried out following the literature [28]. Colchicine and DMSO were used as positive and negative controls, respectively.

\section{Conclusions}

Two new compounds including pinodiketopiperazine A (1) and 6,7-dihydroxy-3-methoxy-3-methyl phthalide (2), as well as two new naturally occurring compounds including alternariol 2,4-dimethyl ether (3) and L-5-oxoproline methyl ester (4), together with six known compounds (5-10) were isolated and identified from the marine sediment-derived fungus Penicillium pinophilum SD-272. The absolute configuration of compound $\mathbf{1}$ was determined by experimental and calculated ECD spectra. Compound $\mathbf{2}$ was found to possess potent lethality with $\mathrm{LD}_{50} 11.2 \mu \mathrm{M}$, while compounds $\mathbf{1}, \mathbf{3}$, and $\mathbf{5}-\mathbf{8}$ displayed inhibitory activity against Escherichia coli, causing the 10.0, 9.0, 8.0, 8.0, 7.0, and $10.0 \mathrm{~mm}$ zones of inhibition, respectively. 


\section{Acknowledgments}

This work was financially supported by Ministry of Science and Technology (2013AA092901 and 2010CB833802) and by National Natural Science Foundation of China (31270403).

\section{References}

1. Blunt, J.W.; Copp, B.R.; Keyzers, R.A.; Munro, M.H.G.; Prinsep, M.R. Marine natural products. Nat. Prod. Rep. 2012, 29, 144-222.

2. Blunt, J.W.; Copp, B.R.; Munro, M.H.G.; Northcote, P.T.; Prinsep, M.R. Marine natural products. Nat. Prod. Rep. 2010, 27, 165-237.

3. Blunt, J.W.; Copp, B.R.; Hu, W.P.; Munro, M.H.G.; Northcote, P.T.; Prinsep, M.R. Marine natural products. Nat. Prod. Rep. 2008, 25, 35-94.

4. Wu, Q.X.; Crews, M.S.; Draskovic, M.; Sohn, J.; Johnson, T.A.; Tenney, K.; Valeriote, F.A.; Yao, X.J.; Bjeldanes, L.F.; Crews, P. Azonazine, a novel dipeptide from a Hawaiian marine sediment-derived fungus, Aspergillus insulicola. Org. Lett. 2010, 12, 4458-4461.

5. Blunt, J.W.; Copp, B.R.; Munro, M.H.G.; Northcote, P.T.; Prinsep, M.R. Marine natural products. Nat. Prod. Rep. 2011, 28, 196-268.

6. Li, C.S.; An, C.Y.; Li, X.M.; Gao, S.S.; Cui, C.M.; Sun, H.F.; Wang, B.G. Triazole and dihydroimidazole alkaloids from the marine sediment-derived fungus Penicillium paneum SD-44. J. Nat. Prod. 2011, 74, 1331-1334.

7. Gao, S.S.; Li, X.M.; Du, F.Y.; Li, C.S.; Proksch, P.; Wang, B.G. Secondary metabolites from a marine-derived endophytic fungus Penicillium chrysogenum QEN-24S. Mar. Drugs 2011, 9, 59-70.

8. Zhao, Y.; Chen, H.; Shang, Z.; Jiao, B.H.; Yuan, B.; Sun, W.Z.; Wang, B.G.; Miao, M.Y.; Huang, C.G. SD118-Xanthocillin X (1), a novel marine agent extracted from Penicillium commune, induces autophagy through the inhibition of the MEK/ERK pathway. Mar. Drugs 2012, 10, 1345-1359.

9. Du, F.Y.; Li, X.M.; Li, C.S.; Shang, Z.; Wang, B.G. Cristatumins A-D, new indole alkaloids from the marine-derived endophytic fungus Eurotium cristatum EN-220. Bioorg. Med. Chem. Lett. 2012, $22,4650-4653$.

10. Sun, H.F.; Li, X.M.; Meng, L.; Cui, C.M.; Gao, S.S.; Li, C.S.; Huang, C.G.; Wang, B.G. Asperolides A-C, tetranorlabdane diterpenoids from the marine alga-derived endophytic fungus Aspergillus wentii EN-48. J. Nat. Prod. 2012, 75, 148-152.

11. Zhang, Y.; Li, X.M.; Shang, Z.; Li, C.S.; Ji, N.Y.; Wang, B.G. Meroterpenoid and diphenyl ether derivatives from Penicillium sp. MA-37, a fungus isolated from marine mangrove rhizospheric soil. J. Nat. Prod. 2012, 75, 1888-1895.

12. Sóti, F.; Incze, M.; Kajtár-Peredy, M.; Baitz-Gács, E.; Imre, L.; Farkas, L. Synthese natürlicher dibenzo- $\alpha$-pyrone, II. Synthese des alternariols und des alternariol-9-methylethers. Chem. Ber. 1977, 110, 979-984.

13. Tan, N.; Tao, Y.W.; Pan, J.H.; Wang, S.Y.; Xu, F.; She, Z.G.; Lin, Y.C.; Jones, E.B.G. Isolation, structure elucidation, and mutagenicity of four alternariol derivatives produced by the mangrove endophytic fungus No. 2240. Chem. Nat. Compd. 2008, 44, 296-300. 
14. Drauz, K.; Kleemann, A.; Martens, J.; Scherberich, P.; Effenberger, F. Amino acids. 7. A novel synthetic route to L-proline. J. Org. Chem. 1986, 51, 3494-3498.

15. Liu, M.T; Lin, S.; Gan, M.L.; Chen, M.H.; Li, L.; Wang, S.J.; Zi, J.C.; Fan, X.N.; Liu, Y.; Si, Y.K.; et al. Yaoshanenolides A and B: New spirolactones from the Bark of Machilus yaoshansis. Org. Lett. 2012, 14, 1004-1007.

16. Hou, X.F.; Yao, S.; Mándi, A.; Kurtán, T.; Tang, C.P.; Ke, C.Q.; Li, X.Q.; Ye, Y. Bicunningines A and B, two new dimeric diterpenes from Cunninghamia lanceolata. Org. Lett. 2012, 14, 460-463.

17. Chou, T.H.; Chen, I.S.; Hwang, T.L.; Wang, T.C.; Lee, T.H.; Cheng, L.Y.; Chang, Y.C.; Cho, J.Y.; Chen, J.J. Phthalides from Pittosporum illicioides var. illicioides with inhibitory activity on superoxide generation and elastase release by neutrophils. J. Nat. Prod. 2008, 71, 1692-1695.

18. Poisel, H.; Schmidt, U. Asymmetrische synthese aromatischer $\alpha$-aminosäuren und $N$-methyl- $\alpha$-aminosäuren.-Synthese von L-Dopa.- - Über die katalytische hydrierung ungesättigter cyclodipeptide. Chem. Ber. 1973, 106, 3408-3420.

19. Jin, S.; Wessig, P.; Liebscher, J. Unusual $\mathrm{C}=\mathrm{C}$ bond migration in 3-ylidene-2,5-piperazinediones. Eur. J. Org. Chem. 2000, 2000, 1993-1999.

20. Fdhila, F.; Vázquez, V.; Sánchez, J.L.; Riguera, R. DD-diketopiperazines: Antibiotics active against Vibrio anguillarum isolated from marine bacteria associated with cultures of Pecten maximus. J. Nat. Prod. 2003, 66, 1299-1301.

21. Kimura, Y.; Yoshinari, T.; Koshino, H.; Fujioka, S.; Okada, K.; Shimada, A. Rubralactone, rubralides A, B and C, and rubramin produced by Penicillium rubrum. Biosci. Biotechnol. Biochem. 2007, 71, 1896-1901.

22. Jiao, P.; Gloer, J.B.; Campbell, J.; Shearer, C.A. Altenuene derivatives from an unidentified freshwater fungus in the family Tubeufiaceae. J. Nat. Prod. 2006, 69, 612-615.

23. Wang, S.; Li, X.M.; Teuscher, F.; Li, D.L.; Diesel, A.; Ebel, R.; Proksch, P.; Wang, B.G. Chaetopyranin, a benzaldehyde derivative, and other related metabolites from Chaetomium globosum, an endophytic fungus derived from the marine red alga Polysiphonia urceolata. J. Nat. Prod. 2006, 69, 1622-1625.

24. ChemAxon, Marvin 5.9.2; ChemAxon Ltd.: Budapest, Hungary, 2012.

25. Bruhn, T.; Hemberger, Y.; Schaumloffel, A.; Bringmann, G. SpecDis, version 1.51; University of Wuerzburg: Wuerzburg, Germany, 2011.

26. Frisch, M.J.; Trucks, G.W.; Schlegel, H.B.; Scuseria, G.E.; Robb, M.A.; Cheeseman, J.R.; Scalmani, G.; Barone, V.; Mennucci, B.; Petersson, G.A.; et al. Gaussian 09, Revision C.01; Gaussian, Inc.: Wallingford, CT, USA, 2010.

27. Al-Burtamani, S.K.S.; Fatope, M.O.; Marwah, R.G.; Onifade, A.K.; Al-Saidi, S.H. Chemical composition, antibacterial and antifungal activities of the essential oil of Haplophyllum tuberculatum from Oman. J. Ethnopharmacol. 2005, 96, 107-112.

28. Gerwick, W.H.; Proteau, P.J.; Nagle, D.G.; Hamel, E.; Blokhin, A.; Slate, D. Structure of curacin A, a novel antimitotic, antiproliferative, and brine shrimp toxic natural product from the marine Cyanobacterium Lyngbya majuscule. J. Org. Chem. 1994, 59, 1243-1245.

(C) 2013 by the authors; licensee MDPI, Basel, Switzerland. This article is an open access article distributed under the terms and conditions of the Creative Commons Attribution license (http://creativecommons.org/licenses/by/3.0/). 